\title{
Globally Optimal R\&D Subsidy Policy: an Economist's View on the WTO Subsidy Agreement
}

\author{
Moonsung Kang \\ Korea University
}

\begin{abstract}
We provide economic backgrounds to the Agreement on Subsidies and Countervailing Measures under the World Trade Organization. Permitting R\&D subsidy under Article 8 of the Agreement can be interpreted as an inefficient victory of an individual exporting country in the non-cooperative game, harnessing strategic relationship over a foreign rival firm into its domestic industrial policy. In addition, we show that the expiration of Article 8 can be understood as a result of the global optimum, where we maximize the sum of welfares over exporting and importing countries in the symmetric case with a linear demand.
\end{abstract}

- JEL classification: F10, F13

- Keywords: Strategic Trade Policy, R\&D subsidies, WTO

\section{Introduction}

Subsidies are generally defined as various state-aid grants to industries or firms in order for their government to achieve specific policy goals. While the use of subsidies is a right of each World Trade Organization (WTO) member country as national sovereignty, some subsidies could intentionally affect competitiveness of a specific industry or a firm, having a trade-distorting effect. To regulate these tradedistorting subsidies, the WTO established disciplines on subsidies in the

\footnotetext{
*Corresponding address: Moonsung Kang, Assistant Professor, Division of International Studies, Korea University, 5-1 Anam-dong, Sungbuk-Gu, Seoul, 136-701, Korea, Tel: +82-2-3290-2420, Fax: +82-23290-2420, E-mail: mkang@korea.ac.kr

C2008-Center for International Economics, Sejong Institution, All Rights Reserved.
} 
Agreement on Subsidies and Countervailing Measures (SCM) as a result of the Uruguay Round (UR). ${ }^{1}$

During the UR, it was very controversial to define trade-distorting subsidies, but member countries agreed to prohibit both export subsidies and import substitution subsidies, ${ }^{2}$ because subsidization may pertain to import-competing industries or export industries that compete in international markets. In the history of the multilateral trade negotiations (MTNs), some countries had a strong belief that subsidization may threaten to offset market-opening commitments negotiated in the MTNs if such subsidization distorts trade. This verifies why WTO member countries agreed to prohibit both export subsidies and import substitution subsidies. However, they decided to permit R\&D subsidies, including assistance to industrial research and pre-competitive development activity (Article 8.2(a) of the SCM Agreement), ${ }^{3}$ even though this "green" ${ }^{4}$ category of subsidies had applied for a period of five years from the date of entry into force of the WTO Agreement, that is, this provision has been expired since Year 2000 (Article 31 of the SCM Agreement).

Previous literature on R\&D subsidies, including Spencer and Brander (1983), provided economic logics to a government's incentive to provide $R \& D$ subsidies. A central message of the theory is the profit shifting, under which a foreign rival firm's profits are shifting to the domestic firm when a government subsidizes its domestic firm. However, it is a puzzle that WTO member countries have recognized $R \& D$ subsidies on a provisional basis of the five-year period, even though governments are very active to subsidize their domestic firms. In this paper,

${ }^{1}$ The SCM Agreement defines a subsidy as a financial benefit conferred either directly or indirectly by a government or any public body (Article 1.1 of the SCM Agreement).

${ }^{2}$ Export subsidies are those contingent, in law or in fact, upon export performance (Article 3.1(a) of the SCM Agreement); and import substitution subsidies are those contingent upon the use of domestic over imported goods (Article 3.1(b) of the SCM Agreement).

${ }^{3}$ In addition, member countries agreed to permit assistance to disadvantaged regions (regional development subsidies, Article 8.2(b) of the SCM Agreement) and certain types of assistance for adapting existing facilities to new environmental requirements (environment subsidies, Article 8.2(c) of the SCM Agreement).

${ }^{4}$ In general, we understand that the SCM Agreement adopted a "traffic light" approach to categorize subsidies. The Agreement classifies kinds of subsidies as unlikely to cause harm to trade ("green"), and some as harmful and therefore to be prohibited ("red"). In addition, some are in a ("yellow") category of subsidies which are open to challenge only if they cause adverse effects. Please see Croome (1999: 90-91) for more detail information. 
we provide economic backgrounds on the SCM Agreement by answering to this puzzle.

Following Spencer and Brander (1983), in this paper we adopt a standard trade model having two exporting countries with $R \& D$ rivalry and an importing country. In a non-cooperative setup, we earn an identical result to that of Spencer and Brander (1983), but show that this result is not Pareto efficient. And then we explore the joint optimum, where both exporting countries cooperate to set $R \& D$ policy and show the jointly optimal $R \& D$ policy is to impose a tax on $R \& D$ activities, identical to one of key results of Spencer and Brander (1983). By considering the third importing country's welfare, we seek the globally optimal R\&D subsidy policy. Comparing these results in tandem, we provided economic backgrounds to the SCM Agreement. First, permitting R\&D subsidy under Article 8 of the SCM Agreement can be interpreted as an inefficient victory of each individual exporting country in the non-cooperative game, actively harnessing strategic relationship over the foreign rival firm into its domestic industry policy. In addition, it is shown that importing countries have no reason to object this agreement because exporting countries' $R \& D$ subsidies will increase their consumer surplus. However, it turns out that this forms a game of a prisoner's dilemma. Considering the globally optimal R\&D policy, we show that the expiration of Article 8, permitting R\&D subsidy, can be understood as a result of the global optimum, where we maximize the sum of welfares over exporting and importing countries in the symmetric case with a linear demand.

In the field of strategic trade policy, economic backgrounds of governments' incentive to subsidize have been a critical issue, with the seminal paper by Spencer and Brander (1983). In general, the use of subsidies makes domestic firms more aggressive under the Cournot competition, leading foreign firms to reduce their production. Therefore, subsidies can alter strategic relations between domestic and foreign firms, implying that use of subsidies can generate "first-mover's advantage" in a general oligopoly setup.

Incentives to change strategic relations mentioned above can be also interpreted as those to alter terms of trade, that is, a government has an incentive to change terms of trade in a direction favorable to its domestic firms as shown in Bagwell and Staiger (2002: 28-30, 2004) and Crowley (2006). Therefore, governments would have a strong incentive to subsidize their domestic firms under which there are no binding trade agreements and hence they are allowed to unilaterally set their subsidy policy. However, this paper explains what kind of economic backgrounds 
can be understood on the expiration of Article 8, permitting R\&D subsidies, of the SCM Agreement.

The paper proceeds as follows. Section II presents a basic model to analyze the SCM Agreement, following Spencer and Brander (1983). Section III describes optimal R\&D policies under non-cooperative, cooperative, and global perspectives, respectively. In addition, we provide economic backgrounds on the SCM Agreement using our findings in Section III. Section IV concludes.

\section{Basic Model}

\section{A. Basic Setup}

We introduce a standard trade model based on Spencer and Brander (1983, hereafter SB model) and extend it to provide an economic background of WTO SCM Agreement. In this model, there are two exporting countries, home (no*) and foreign $(*)$, with a single exporting firm, and a third importing country. Both exporting firms play in a single game where firms choose output levels (Cournot competition). We consider policy choices of subsidies in several ways. First, each exporting country's government is allowed to set simultaneously its subsidy level in the Nash setup. Secondly, both home and foreign countries cooperate over subsidy policies. Finally, we seek globally optimal R\&D subsidy policy from the world point of view including the third importing country.

We analyze a three-stage game, in which both home and foreign governments simultaneously choose their own R\&D subsidy rates $\left(s, s^{*}\right)$ in the first stage and then each firm simultaneously levels of $\mathrm{R} \& \mathrm{D}$ investment $\left(x, x^{*}\right)$ and output $\left(y, y^{*}\right)$ in the second and third stages, respectively. We use the idea of backward induction to find a sub-game perfect equilibrium. Thus, we start by solving for the optimal choice of firms for each possible situation, and then work backward to compute the optimal choice for the governments.

\section{B. Output Stage}

Now, let us begin by analyzing the last stage in order to find a sub-game perfect equilibrium. A domestic firm produces output $y$ at $\operatorname{cost} C(y ; x)$, which induces all costs, and earns revenue $R$. The R\&D investment level of the domestic firm in the home country is denoted $x$ and costs $v$ per unit. The government provides R\&D subsidies (tax if negative) at a rate of $s$. Profits of this firm are then given as 
follows:

$$
\pi\left(y, y^{*} ; x, s\right)=R\left(y, y^{*}\right)-C(y ; x)-(v-s) x
$$

Following the SB model, outputs $y$ and $y^{*}$ are substitutes and it is assumed that an increase in the foreign output decreases the marginal revenue of the domestic firm:

$$
R_{y}>0 ; R_{y^{*}}<0 ; R_{y y^{*}}<0 .^{5}
$$

The production cost of the domestic firm depends on domestic output level and it is assumed that marginal cost is constant and there is no fixed cost: $\mathrm{C}(y ; x)=$ $c(x) y$, where $c(x)>0$ is marginal cost. An increase in $\mathrm{R} \& \mathrm{D}$ investment reduces the marginal cost: $c_{x}<0$.

The domestic firm faces the following optimization problem:

$$
\max \pi\left(y, y^{*} ; x, s\right)=R\left(y, y^{*}\right)-C(y ; x)-(v-s) x .
$$

The Nash equilibrium output level that maximizes profits can be characterized by the first-order and the second-order conditions as follows:

$$
\begin{aligned}
& \pi_{y}=R_{y}-c=0 ; \text { and } \\
& \pi_{y y}=R_{y y}<0 .
\end{aligned}
$$

Then the solutions to the first-order conditions can be written as:

$$
y=q\left(x, x^{*}\right) ; \text { and } y^{*}=q^{*}\left(x, x^{*}\right) .
$$

Totally differentiating the first-order conditions with respect to $y$ and $y^{*}$, we can show the slope of the output reaction function, which is negative from (2) and the second-order conditions:

Home $d y / d y^{*}=-R_{y y} / R_{y y}<0$; and Foreign $d y * / d y=-R_{y^{*} y}^{*} / R^{*} y^{*} y^{*}<0$.

\footnotetext{
${ }^{5}$ In this paper, we use subscripts to denote partial derivatives.
} 
Thus each firm's output reaction curve is downward sloping because outputs are substitutes. Using comparative analyses, we can show the same results earned in Spencer and Brander (1983): home (foreign) R\&D activities raise home (foreign) output production, but reduce foreign (home) output production:

$$
\begin{aligned}
& d y / d x=c_{x} R^{*}{ }_{y^{*} y^{*}} / A>0 ; d y * / d x=-c_{x} R^{*}{ }_{y^{*}} / A<0 ; d y / d x^{*}=-c^{*} x^{*} R_{y y} / A<0 ; \text { and } \\
& d y * / d x^{*}=c^{*}{ }_{x^{*}} R_{y y} / A>0, \text { where } A R_{y y} R^{*}{ }_{y^{*} y^{*}}-R_{y y *} R^{*}{ }_{y^{*}}>0 .
\end{aligned}
$$

\section{R\&D Investment Stage}

Given the analysis of the output stage in which R\&D investment levels are treated as exogenous, we now focus on the $R \& D$ investment stage, in which exporting firms simultaneously choose their R\&D investment level. For this, each exporting firm's profit function can be rewritten as a function of $x$ and $x *$. Let $G$ represent the profit function for the domestic firm and then the domestic firm faces the following maximization problem:

$$
G\left(x ; x^{*}, s\right) \equiv p\left(q\left(x, x^{*}\right), q^{*}\left(x, x^{*}\right), x ; x^{*}, s\right)
$$

Using the first- and second-order conditions of this profit maximization problem, we can characterize the Nash equilibrium R\&D investment levels, $z$ and $z *$ :

$$
\begin{aligned}
& \mathrm{R}_{\mathrm{q}^{*}} \mathrm{q}^{*}{ }_{\mathrm{x}}-\mathrm{qc}_{\mathrm{x}}-(\mathrm{v}-\mathrm{s})=0 ; \\
& R_{q^{*}}\left(d q^{*}{ }_{x} / d x\right)+q^{*}{ }_{x}\left(d R_{q^{*}} / d x\right)-q_{x} c_{x}-q c_{x x}<0 ; \text { and } \\
& z \equiv x\left(s, s^{*}\right) ; z^{*} \equiv x^{*}\left(s, s^{*}\right) .
\end{aligned}
$$

Totally differentiating the first-order condition and using the previous results, we can show that R\&D investment levels are substitutes:

Home $d x / d x^{*}=-G_{x x^{*}} / G_{x x}<0$; Foreign $d x * / d x=-G^{*} x^{*} / G^{*} x^{*} x^{*}<0$.

In addition, we can show using comparative analysis of this stage that $R \& D$ subsidies in home (foreign) country raise home (foreign) R\&D investment, but reduce foreign (home) $R \& D$ investment:

$$
d x / d s=-G^{*} x_{x^{*} x^{*}} / B>0 ; d x^{*} / d s=G_{x^{*}{ }^{*}} / B<0 \text {, where } B G_{x x} G^{*} x^{*} x^{*}-G_{x x^{*}} G^{*}{ }_{x^{*} x}>
$$

0 . 


\section{Policies on R\&D Subsidies}

\section{A. Non-Cooperative Policy Choices without Any Binding Agreement}

We first characterize non-cooperative Nash policy choices without any binding agreement. Since we analyzed the second stage in which R\&D subsidies are treated as exogenous, we focus on the first stage hereafter. When governments do not cooperate over policies, the home government is assumed to unilaterally set a subsidy rate to maximize its domestic welfare, the domestic firm's profits less subsidy costs:

$$
\max W\left(s ; s^{*}\right)=G\left(z\left(s, s^{*}\right), z^{*}\left(s, s^{*}\right), s\right)-s z\left(s, s^{*}\right) .
$$

The foreign country faces a similar problem:

$$
\max W^{*}\left(s^{*} ; s\right)=G^{*}\left(z^{*}\left(s^{*}, s\right), z\left(s^{*}, s\right), s^{*}\right)-s^{*} z^{*}\left(s^{*}, s\right) .
$$

Since the main result of these optimization problems is similar to Spencer and Brander (1983), we report here the key aspects of the result as follows:

The Non-Cooperative Nash Equilibrium without Any Binding Agreement $s^{N}=G_{z^{*}}\left(d z^{*} / d z\right)>0$; and $s^{* N}=G_{z}^{*}\left(d z / d z^{*}\right)>0$.

This equilibrium implies that each exporting country has an incentive to subsidize its domestic firm in the Nash setup.

Is the Nash policy set, $\left(s^{N}, s^{* N}\right)$, Pareto efficient, then? By analyzing the slopes of each country's iso-welfare contour, one can show the following:

\section{Proposition 1: Inefficiency of Nash Equilibrium}

Nash equilibrium subsidy rates $\left(s^{N}, s^{* N}\right)$ are Pareto inefficient.

Proof. For a pair of Nash equilibrium subsidy rates $\left(s^{N}, s^{* N}\right)$ to be Pareto efficient, the following condition must hold: $\left.\left(d s / d s^{*}\right)\right|_{d W=0}=\left.\left(d s / d s^{*}\right)\right|_{d W^{*}=0}$, that is, both countries' iso-welfare contours need to have the same slope on the space of ( $s$, $\left.s^{*}\right)$. The first-order condition of (P2) is: $W_{s}\left(s, s^{*}\right)=G_{z} * z_{s}-s z_{s}=0$. Totally differentiating this with respect to $s$ and $s^{*}$, one can find $\left.\left(d s / d s^{*}\right)\right|_{d W=0}=-W_{s s^{*}} / W_{s s}$. 
Using the similar method, one can find $\left.\left(d s / d s^{*}\right)\right|_{d W^{*}=0}=-W^{*}{ }_{s^{*}} / W^{*}{ }_{s^{*}}$. Since $W_{s s}$ $=-z_{s}, W_{s s^{*}}=0, W^{*}{ }^{*} s^{*}=-z^{*} s^{*}$, and $W^{*} s^{*}=0$, one can show $\left.\left(d s / d s^{*}\right)\right|_{d W=0}=0$ $<\infty=\left.\left(d s / d s^{*}\right)\right|_{d W^{*}=0}$

As $<$ Figure 1> shows, at the Nash equilibrium point $N$, the slope of the home (foreign) iso-welfare contour is horizontal (vertical), reflecting the fact that from this point neither government can improve its payoff with a unilateral change in its subsidy policy. The outcome at $N$ clearly represents an inefficient combination of subsidy choices, as at this point the home and foreign iso-welfare contours are not tangent to each other.

Why is the Nash equilibrium Pareto inefficient, then? It is because the Nash setup creates a general form of a prisoner's dilemma on subsidization due to strategic externalities. As we discussed in the previous section, while each exporting country has an incentive to subsidize its domestic firm, both exporting countries would be worse off in the case of two active governments than in the case of free trade without any intervention from governments. The active intervention forming the strategic externalities distorts the efficiency. We will check in the next subsection how a Pareto improvement could be achieved through an international agreement or cooperation.

Figure 1. Pareto Inefficiency of the Nash Equilibrium

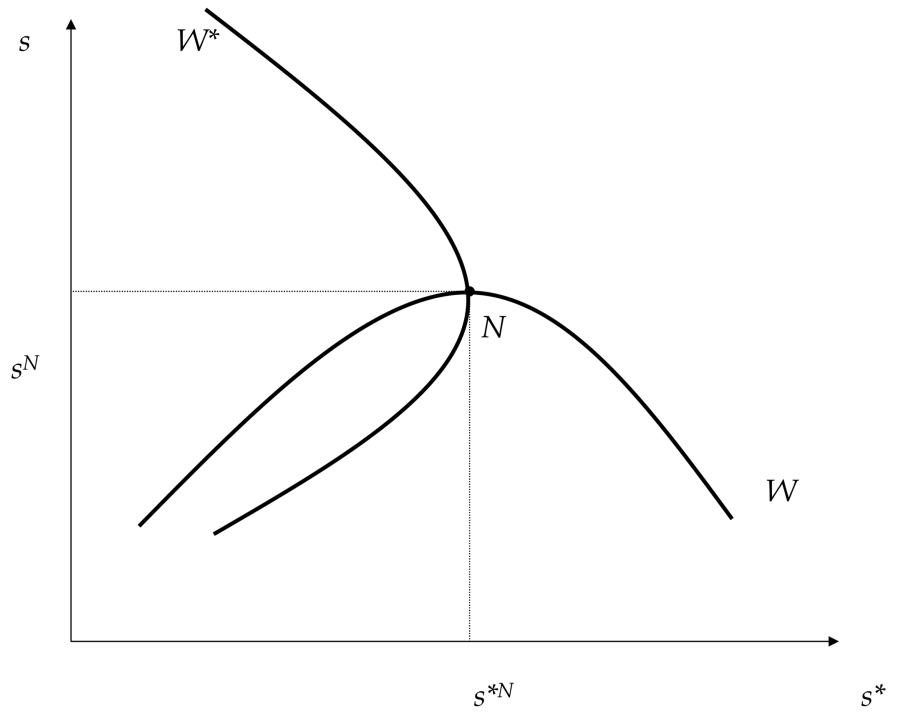




\section{B. Joint Optimum among Exporting Countries}

Now suppose that both exporting countries cooperate over subsidy policies in order to maximize the joint welfare of the exporting countries. Then the optimization problem is given as follows:

$$
\max W\left(s, s^{*}\right)+W^{*}\left(s, s^{*}\right)
$$

Again since the main result of these optimization problems is similar to Spencer and Brander (1983), we report here the key aspects of the result as follows:

Joint Optimum of Exporting Countries

$s^{C}=G_{z}^{*}<0 ; s^{* C}=G_{z^{*}}<0$.

Proof. Since $R_{q}^{*}<0$ and $q_{z}>0$, we can show $G_{z}^{*}=R^{*}{ }_{q} q_{z}<0$, implying $s^{C}<0$. It turns out that both exporting countries would impose a tax rather than provide subsidies when they cooperate over policies. This is because they figured out that the strategic externalities negatively affect their domestic firms by making them overproduce. Thus, this result suggests that both exporting countries need to impose a tax on production by internalizing the negative externality.

\section{Global Optimum}

Now, let us consider a global optimization problem in which each country sets its subsidy policy cooperatively to maximize worldwide welfare. Then we will check how the results of this optimization problem support the SCM Agreement. Since there are two exporting countries and a third importing country in our setup, we can form the worldwide welfare function just adding the third country's welfare function to the function of (P4). Since the importing country is the only place that consumption occurs with no production in the model, the consumer surplus (CS) represents the importing country's welfare:

$$
C S\left(s, s^{*}\right)=\int_{0}^{q^{E} s+q^{*}{ }^{*}} p(t) d t-p^{E}\left(s, s^{*}\right)\left(\left[q^{E}\left(s, s^{*}\right)+q^{* E}\left(s, s^{*}\right)\right], \quad\right)
$$

where $p(i)$ is an inverse demand function for the final good. The maximization problem is given as follows:

$\max W W W\left(s, s^{*}\right)=W\left(s, s^{*}\right)+W^{*}\left(s, s^{*}\right)+C S\left(s, s^{*}\right)$. 
The first-order condition of (P5) is given as follows:

$$
\begin{aligned}
& W W W_{s}=W_{s}+W^{*}{ }_{s}+C S_{s} \\
& =G_{z} z^{*}{ }_{s}-s z_{s}+G^{*} z_{s}-s^{*} z_{s}-\left(q+q^{*}\right)(d p / d q)\left(z_{s}+z^{*}\right)\left(q_{z}+q_{z}^{*}\right)=0 .
\end{aligned}
$$

Using $W W W_{s^{*}}=0$ and solving (12) for $s$ and $s^{*}$, one can show the globally optimal subsidy rate as follows:

\section{Global Optimum}

$s^{G}=G_{z}^{*}-\left(q+q^{*}\right)(d p / d q)\left(q_{z}+q_{z}^{*}\right) ;$ and $s^{* G}=G_{z^{*}}-\left(q+q^{*}\right)\left(d p / d q^{*}\right)\left(q_{z^{*}}^{*}+\right.$ $q_{\left.z^{*}\right) .}$

These globally optimal R\&D rates have two important points. First, the globally optimal R\&D subsidy rate $\left(s^{G}\right)$ is the level, where both strategic externality and effects on consumer surplus are globally considered. As we discussed above in a non-cooperative setting, each government selected its best response having understood the strategic externalities of the rival firm's activities. Thus, each exporting country has an incentive to provide R\&D subsidies to the domestic firm in the non-cooperative game: $s^{N}>0$. In a cooperative setting, both governments of exporting countries tried to internalize these strategic externalities by imposing a tax on R\&D activities: $s^{C}<0$. However, the globally optimal R\&D policy needs to consider the welfare of consumers in the importing country as well as the strategic externalities between exporting firms.

Secondly, the signs of the globally optimal R\&D subsidy rates are uncertain. Notice that the first term $\left(G_{z}^{*}\right)$, which is negative, is just equal to the jointly optimal level for exporting countries, while the second term $\left[\left(q+q^{*}\right)(d p / d q)\left(q_{z}+\right.\right.$ $\left.q_{z}^{*}\right)$ is also negative. Thus, we can say at least that the globally optimal level seems greater than the jointly optimal level: $s^{G}>s^{C}$. It presumably implies that consumers in the importing country would benefit from cheaper final goods led by R\&D subsidies from exporting countries: $C S_{s}>0 .^{6}$

In order to provide more implications to the sign of the global optimum, let us assume that the demand function of the final good is linear: $p=a-b\left(y+y^{*}\right)$, where $a>0$ and $b>0$. In addition, let us assume that both exporting countries in Home and Foreign countries are identical for simplicity. Then one can have the

\footnotetext{
${ }^{6}$ See Appendix for the proof.
} 
following result on the globally optimal R\&D policy.

\section{Global Optimum in the Symmetric Case with a Linear Demand ${ }^{7}$} $s^{G}=s^{* G}=0$.

It turns out that even though each country has a strong incentive to subsidize $\mathrm{R} \& \mathrm{D}$ activities in the Cournot setup $\left(s^{N}>0\right)$, in the symmetric case with a linear demand the globally optimal R\&D subsidy level is zero and hence between noncooperative Nash level and cooperative level: $s^{N}>s^{G}=0>s^{C}$.

\section{Interpretation on Our Findings}

How can we explain the SCM Agreement using our findings, then? As we discussed previously, WTO member countries agreed as a result of the UR to permit R\&D subsidies, but only on a provisional basis for five years. The "green" category of R\&D subsidies can be understood as a result of concerns of each individual exporting country and importing countries. As we saw previously, each exporting country has an incentive to provide R\&D subsidies: $s^{N}>0$. In addition, consumer surplus in the third importing country has positive benefits from exporting countries' R\&D subsidies: $C S_{s}>0$. Therefore, R\&D subsidies were permitted because during the UR negotiation most countries had been already active to provide $R \& D$ subsidies to their domestic industries and importing countries had no reason to ask exporting countries to reduce their R\&D subsidies.

\section{Proposition 2: R\&D Subsidies as the "Green" Category}

$R \& D$ subsidy as the "green" one under the SCM Agreement can be interpreted as an inefficient victory of each exporting country in the non-cooperative game, actively adopting strategic externalities. In addition, importing countries have no reason to object this agreement.

However, as we figured out previously, exporting countries' R\&D subsidies form a game of a prisoner's dilemma as analyzed in Brander (1995: 1409-1410) and they will be better off by cooperatively imposing a tax on R\&D activities: $s^{C}<$ 0 . It has two important implications. First, a tax policy on R\&D activities can not be hold because each exporting country has an incentive to deviate from this

\footnotetext{
${ }^{7}$ See Appendix for the proof.
} 
cooperative result by providing R\&D subsidies: $s^{N}>0$. Secondly, importing countries are worse off when exporting countries impose a tax on R\&D activities.

By considering the third importing country's welfare, we calculated the globally optimal R\&D subsidies, which was zero in the symmetric case with a linear demand. Thus, expiration of permitting R\&D subsidies can be understood as a result of the global optimum, where the Agreement considered interests of both exporting and importing countries in the symmetric case with a linear demand.

\section{Proposition 3: Expiration of the Article on R\&D Subsidies}

Article 8, permitting $R \& D$ subsidy, was expired since the end of Year 1999. It can be understood as a result of the global optimum, where one considers concerns over both exporting and importing countries in the symmetric case with a linear demand.

\section{Conclusion}

In this paper, we analyzed optimal $R \& D$ policy from three different perspectives, including a non-cooperative game, a cooperative game over exporting countries, and a global optimum. In the non-cooperative game, it was shown as in Spencer and Brander (1983) that each exporting country has an incentive to provide R\&D subsidies. However, when they are able to cooperate over R\&D subsidies, they would better impose a tax on R\&D activities to reduce overproduction occurred in the non-cooperative setup. When we considered the third importing country, the sign of the globally optimal R\&D policy was uncertain but zero in the symmetric case with a linear demand.

Using these findings, we provided economic backgrounds to the SCM Agreement, specifically permitting $R \& D$ subsidies under the initial disciplines and expiration of the article where R\&D subsidies were permitted. Permitting R\&D subsidy under Article 8 of the SCM Agreement can be interpreted as an inefficient victory of each exporting country in the non-cooperative game, actively adopting strategic externalities. In addition, importing countries have no reason to object this agreement. However, this forms a game of a prisoner's dilemma. Therefore, the expiration of Article 8, permitting R\&D subsidy, can be understood as a result of the global optimum, where one considers exporting and importing countries in the symmetric case with a linear demand.

This research has several limits. First, we did not consider any legal perspective 
and negotiating history of disciplines on subsidies because these issues are out of bound in this paper. In addition, it is known that R\&D subsidies are deeply related to protection of intellectual property rights (IPRs) as shown in Kang (2006), because an exporting country's assistance to domestic R\&D activities could flow into a rival country whose IPR protection is not perfectly enforced. This point implies that disciplines on R\&D subsidies must be considered in tandem with issues of trade-related intellectual property rights. We leave this extension to our future work such as Kang (forthcoming).

Received 29 March 2007, Accepted 31 October 2007

\section{References}

Bagwell, K., Staiger, R. W. (2002) The Economics of the World Trading System, Cambridge: The MIT Press

(2004), "Subsidy Agreements," NBER Working Paper Series No. 10292, Cambridge, MA: National Bureau of Economic Research

Brander, J. A. (1995), "Strategic Trade Policy," in Handbook of International Economics: Volume 3 (Eds.) Grossman, G. M., Rogoff, K., New York: North-Holland, pp. 13951455

Croome, J. (1999), Guide to the Uruguay Round Agreements, Hague: Kluwer Law International

Crowley, M. (2006), "The Agreement on Subsidies and Countervailing Measures: Tying One's Hand through the WTO," FRB of Chicago Working Paper No. 2006-22, Chicago, IL: Federal Reserve Bank of Chicago

Kang, M. (2006), "Trade Policy Mix: IPR Protection and R\&D Subsidies," Canadian Journal of Economics 39-3, pp.744-757

(forthcoming), "Understanding Agreements on TRIPS and Subsidies in Tandem," Open Economies Review.

Spencer, B. J., Brander, J. A. (1983), "International R\&D rivalry and industrial strategy," Review of Economic Studies, 50(4), October, 707-722 


\section{Appendix}

\section{Proof of Positive Effects of Subsidies on Consumer Surplus}

From (12), we can show that $C S_{s}=-\left(q+q^{*}\right)(d p / d q)\left(z_{s}+z^{*}{ }_{s}\right)\left(q_{z}+q^{*}\right)$. Since $d p / d q<0$, we know that $\operatorname{sign}\left(C S_{s}\right)=\operatorname{sign}\left[\left(z_{s}+z_{s}^{*}\right)\left(q_{z}+q_{z}^{*}\right)\right]$. First, we can show that $z_{s}+z^{*}>0$ using (10) and its stability condition of $\left|G^{*} z^{*} z^{*}\right|>\left|G^{*} z^{*} z\right|$. For the second part of $\operatorname{sign}\left[\left(z_{s}+z_{s}{ }_{s}\right)\left(q_{z}+q_{z}^{*}\right)\right]$, we can also show that $q_{z}+q_{z}^{*}>0$ using (7) and its stability condition of $\left|R_{q^{*} q^{*}}^{*}\right\rangle\left|R_{q^{*} q}\right|$. Thus, the effect of R\&D subsidy on the consumer surplus, $C S_{s}$, is positive.

\section{Proof of Global Optimum in the Symmetric Case with a Linear Demand}

The globally optimal R\&D subsidy rate is defined as follows: $s^{G}=G_{z}^{*}-(q+$ $\left.q^{*}\right)(d p / d q)\left(q_{z}+q^{*}\right)$. Using the profit maximization condition of $R^{*} q^{*}=c^{*}$, one can show that $G_{z}^{*}=R^{*} q_{z}+R_{q^{*}}^{*} q_{z}^{*}-c^{*} q^{*}{ }_{z}=R^{*} q_{z}$. Since $R^{*}{ }_{q}=(d p / d q) q^{*}$, we can write that $s^{G}=R^{*}{ }_{q} q_{z}-\left(q+q^{*}\right)(d p / d q)\left(q_{z}+q^{*}\right)=(d p / d q) q^{*} q_{z}-\left(q+q^{*}\right)(d p /$ $d q)\left(q_{z}+q_{z}^{*}\right)=-(d p / d q)\left[q\left(q_{z}+q_{z}^{*}\right)+q^{*} q_{z}^{*}\right]$. Using (7), we can show that $s^{G}=$ - $(d p / d q)\left[q c_{z}\left(R_{q^{*} q^{*}}-R_{q^{*} q}^{*}\right) / A-q^{*} c_{z} R_{q^{*} q} / A\right]$. Implying the assumption of a linear demand, $p=a-b\left(y+y^{*}\right)$, where $a>0$ and $b>0$, and using $R^{*}{ }_{q^{*} q^{*}}=-2 b$ and $R_{q^{*} q}=-b$, we can rewrite that $s^{G}=b^{2} c_{z}\left(q^{*}-q\right) / A$. In the symmetric case over two exporting firms, one can show that $s^{G}=0$ because $q=q^{*}$. 